\title{
EDUCAÇÃO EM TEMPO INTEGRAL EM PONTE NOVA/MG: MAS, QUAL EDUCAÇÃO INTEGRAL?
}

\author{
Saraa César Mól ${ }^{1}$ \\ Wanderley Cardoso de Oliveira² \\ Lígia Martha Coimbra da Costa Coelho ${ }^{3}$
}

\begin{abstract}
RESUMO: A ideia da educação integral, no século XXI, tem sido alvo de investimentos por parte de políticas públicas governamentais, associada à educação em tempo integral. Nesse cenário, destacou-se o "Programa Mais Educação" (PME), instituído em 2007 pelo governo federal, com o intuito de induzir uma educação integral em tempo integral. Mas, qual educação integral o PME visou induzir e que especificidades possivelmente tomaram sua materialização? Assim, este artigo busca investigar que educação integral foi materializada em uma escola pública do município de Ponte Nova/MG, a partir do PME, no ano de 2014. Numa abordagem qualitativa, utilizamos como instrumentos de coleta de dados a pesquisa bibliográfica, a pesquisa documental, além da observação, questionários e entrevistas com gestores da escola. Concluímos duvidando da educação em tempo integral do PME como fator propiciador de uma educação integral que considere as especificidades da escola, inclusive na experiência pesquisada.
\end{abstract}

Palavras-chave: Educação integral. Escola de tempo integral. Escola pública.

\footnotetext{
${ }^{1}$ Mestre em Educação. Doutoranda em Educação pela Universidade Federal do Estado do Rio de Janeiro (UNIRIO). Rio de Janeiro-RJ/Brasil. E-mail saraa_mol@ymail.com

${ }^{2}$ Doutor em Educação. Professor titular da Universidade Federal de São João Del-Rei (UFSJ). São João Del-Rei- MG./Brasil. Email.woli@ufsj.edu.br

${ }^{3}$ Doutora em Educação. Professora associada da Universidade Federal do Estado do Rio de Janeiro (UNIRIO). Rio de JaneiroRJ/Brasil. E-mail.ligiamartha25@outlook.com
} 


\section{FULL-TIME EDUCATION IN PONTE NOVA/MG: BUT WHICH IS INTEGRAL EDUCATION?}

ABSTRACT: The idea of integral education, in the 21st century, has been the target of investments by government public policies, associated with full-time education. In this scenario, the "Mais Educação Program" (PME), instituted in 2007 by the Brazilian federal government, was highlighted to induce a full-time integral education. But which integral education did the PME aim to induce and which specificities possibly took its materialization? Thus, this article seeks to investigate which integral education was materialized in a public school in the city of Ponte Nova/MG, based on the PME, in the year of 2014. In a qualitative approach, we used as instruments of data collection the bibliographic research, the documentary research, as well as observation, questionnaires and interviews with school managers. We conclude doubting the full-time PME education as a propitiating factor for an integral education that considers the specificities of the school, also in the researched experience.

Keywords: Integral education; Full-time school. Public school.

\section{EDUCACIÓN EN TIEMPO INTEGRAL EN PONTE NOVA/MG: ¿QUÉ EDUCACIÓN INTEGRAL?}

RESUMEN: La idea de educación integral, en el siglo XXI, ha sido el objetivo de las inversiones por las políticas públicas de gobierno, publicando políticas asociadas con la educación en tiempo integral. En ese contexto, el "Programa Mais Educação" (PME), instituido en 2007 por el gobierno federal brasileño, fue restablecido para llevar a cabo una educación integral en tiempo integral. ¿Pero cuál es la educación integral que el PME ha intentado inducir y qué especificidades posiblemente tomaron su materialización? Así, este artículo busca investigar que educación integral fue materializada en una escuela pública del municipio de Ponte Nova/MG, a partir del PME, en el año de 2014. En un estudio cualitativo, utilizamos como instrumentos de recolección de datos la investigación bibliográfica, la investigación documental, así como la observación, la investigación y la entrevista con los gerentes de la escuela. Concluimos dudando de la educación a tiempo integral del PME como factor propiciador de una educación integral que considere las especificidades de la escuela, incluso en la experiencia investigada.

Palavras chave: Educación integral. Escuela a tiempo integral. Escuela pública 
A história da educação em tempo integral no Brasil, apesar de não ser recente, foi notadamente marcada pelo Programa Mais Educação (PME), iniciativa federal instituída em 2007 como uma estratégia de indução da ampliação da jornada escolar, sob a perspectiva de uma educação integral, no âmbito das escolas públicas de Ensino Fundamental. Se utilizamos o conceito de educação em tempo integral do próprio Programa, ou seja, a jornada igual ou superior a sete horas diárias, considerando o período total em que o aluno permanece na escola ou em atividades escolares em outros espaços educacionais (BRASIL, 2010), podemos entender que o PME visava induzir, então, uma perspectiva de educação integral em tempo integral.

De 54 municípios em 2008, em 2013, o PME estava implantado em 4.936 municípios, estando presente em $86,9 \%$ dos municípios brasileiros, o que representou um crescimento de 8.855,5\% (BRASIL, 2013). A queda no repasse dos recursos às escolas, notadamente a partir de 2015, sem dúvida diminuiu a capilaridade do Programa, que em 2016 foi substituído por outro projeto.

Numa proposta diferenciada de experiências que marcaram o século XX no Brasil e tinham, no fortalecimento da estrutura da escola, seu diferencial, tais como o Centro Educacional Carneiro Ribeiro (CECR) na Bahia, nos anos 1950, e os Centros Integrados de Educação Pública (CIEP), no Rio de Janeiro nos anos 1980, o PME associou a ideia de educação integral à proteção social e à educação intercultural, congregando outros sujeitos e outros saberes para além daqueles historicamente correlatos à escola, que assumiu, assim, outras funções, procurando ampliar a "educação comum", assim como posta por Libâneo (2014).

Importante se faz investigar qual a educação integral materializada no contexto de uma escola pública do município de Ponte Nova/MG, a partir do Programa Mais Educação (PME), entendendo que este processo acarreta "interdições, redirecionamentos, conforme os interesses políticos, econômicos, e o universo simbólico-cultural instituídos pelos poderes locais" (SILVA; SILVA, 2014, p. 3). Trata-se, no caso desta pesquisa, de uma escola pública do município de Ponte Nova/MG.

Numa abordagem qualitativa (BOGDAN; BIKLEN, 1994), a investigação lançou mão da pesquisa bibliográfica (CAVALIERE, 2007, 2013; COELHO, 2014; LIBÂNEO, 2014, 2016; MOLL, 
2012; SILVA, 2013; SILVA; SILVA, 2014), da pesquisa documental, especialmente a partir de documentos do PME, além da observação, de questionários e de entrevistas com gestores da escola. A análise dos dados orientou-se por eixos ligados aos objetivos do PME; à organização dos tempos e espaços educativos, além de sua lógica curricular. 0 artigo apresenta, no primeiro tópico, a concepção de educação integral em tempo integral do Programa. Em seguida, sua materialização na escola pesquisada, a partir dos referidos eixos e, então, expõe alguns elementos (in)conclusivos acerca da pesquisa em questão.

\section{Programa Mais Educação: mais de qual educação?}

No seio da Secretaria de Educação Básica (SEB), entre 2011 e 2016 , e da Diretoria de Currículos e Educação Integral, o PME era empreendido de forma intersetorial, sob a responsabilidade de diferentes áreas da gestão pública, e financiado por meio do Fundo Nacional de Desenvolvimento da Educação (FNDE). Ele era repassado diretamente às escolas por meio do Programa Dinheiro Direto na Escola (PDDE) e do Programa Nacional de Alimentação Escolar (PNAE).

No que tange aos critérios para adesão ao Programa e de prioridade dos alunos contemplados, o Manual Operacional de Educação Integral (BRASIL, 2014) indicava as escolas com menores índices no Índice de Desenvolvimento da Educação Básica (IDEB), maior participação dos estudantes no Programa Bolsa Família, assim como estudantes com problemas de aprendizagem, evasão, repetência e defasagem idade-ano.

Posteriormente, a resolução n. 2, de 2016 (BRASIL, 2016) dispôs a adesão ao PDDE em fases, sendo que a primeira englobava escolas com menor rendimento na Prova Brasil.

Para Moll (2012), esses critérios de seleção das escolas no PME contemplavam o caráter de discriminação positiva e de política afirmativa que dimensionavam as ações do programa, constituindo-se estratégia para o enfrentamento das desigualdades sociais historicamente corroboradas pelo sistema educacional com a entrada tardia, e em condições

${ }^{4}$ Nesse recorte de tempo o PME esteve ligado à SEB. No entanto, teve origem na Secretaria de Educação Continuada, Alfabetização, Diversidade e Inclusão (SECADI), no seio da Diretoria de Educação Integral, Direitos Humanos e Cidadania. 
adversas, das camadas populares na escola. Mas, a autora adverte

[...] ao serem destinadas aos segmentos da população que apresentam problemas sociais e escolares graves, essas políticas tendem a afastar, das escolas afetadas, os alunos em melhores condições sociais e escolares (Costa, $2008^{5}$ ). Esse fenômeno, de homogeneização das populações atendidas pelas escolas alvo das políticas especiais, pode autoalimentar os problemas existentes e exercer força antagônica às mudanças esperadas. Se o aumento do tempo de permanência da criança na escola é condição para que se ponha em prática um modelo de organização escolar que possibilite um processo educacional efetivamente democrático, como pretende, por exemplo, a proposta de "educação integral" do Programa Mais Educação, isso seria, em tese, válido para todas as crianças. Entretanto, na prática tanto no citado programa como em diversos outros desenvolvidos em Municípios brasileiros, a proposta de "educação integral" vem sendo dirigida às escolas com menos recursos e àqueles alunos com problemas sociais e escolares (CAVALIERE, 2013, p. 240).

Essa educação em tempo integral "focal" encontrava-se expressa no Decreto n. 7.083, de 2010 (BRASIL, 2010), como “A jornada escolar com duração igual ou superior a sete horas diárias, durante todo o período letivo, compreendendo o tempo total em que o aluno permanece na escola ou em atividades escolares em outros espaços educacionais". As atividades deveriam ocorrer dentro do espaço escolar, de acordo com a disponibilidade da escola, ou fora dele, sob sua orientação pedagógica, a partir dos "territórios educativos", por meio da integração dos espaços escolares com equipamentos públicos, tais como centros comunitários, bibliotecas públicas, praças, parques, museus e cinemas, e do estabelecimento de parcerias com órgãos ou instituições locais (BRASIL, 2010).

A vertente do modelo de organização da ampliação da jornada escolar, que tende a investir em mudanças no interior das instituições escolares, em condições compatíveis com a presença de alunos e professores em tempo integral, é posta por Cavaliere (2007) como "escola de tempo integral". Já aquela, que tende a articular instituições e projetos da sociedade, oferecendo atividades preferencialmente fora do espaço escolar, é nomeada pela mesma autora de "aluno em tempo integral". As propostas que ampliam o tempo educativo das crianças em espaços fora da escola resolvem as dificuldades advindas do confinamento, especialmente, quando as instalações não são próprias, mas trazem o risco da fragmentação

${ }^{5}$ COSTA, Márcio da. Prestígio e hierarquia escolar: estudo de caso sobre diferenças entre escolas em uma rede escolar municipal. Revista Brasileira de Educação, v. 1, n. 39, p. 455-469, set/dez. 2008.

Argumentos Pró-Educação, Pouso Alegre, v. 4, n. 12, p. 1097 - 1117, set. - dez., 2019

ISSN: 2448-2803 http://dx.doi.org/10.24280/ape.v4i12.408 
da ação educativa e sua perda de coerência e sentido, assim nos diz Cavaliere (2013).

Porém, é necessário destacar que:

O modelo [...] centralizado na instituição escolar, ou seja, de escola de tempo integral e não de aluno em tempo integral, também não está livre do espírito assistencialista do "atendimento". Mas é preciso lembrar que a escola é, por natureza, a instituição do aluno e para o aluno. Com todas as suas limitações, é a instituição onde o aluno é sempre a parte principal, onde seu lugar é um direito constitucional. Dependendo de sua proposta, pode vir a ser o local primordial de vida das crianças, onde estas se auto-reconheçam e sejam reconhecidas, onde seus direitos e deveres sejam acordados e respeitados, onde sejam, efetivamente, as protagonistas do processo educacional (CAVALIERE, 2007, p. 1031).

Por meio da escola, mas não apenas nela, pretendia-se propiciar, no âmbito do PME, a formação integral de crianças, adolescentes e jovens; a garantia da proteção e assistência social (BRASIL, 2007); a melhoria da aprendizagem; a promoção do diálogo entre os conteúdos escolares e os saberes locais; o enfrentamento da violência, a integração entre escola e comunidade (BRASIL, 2010).

Percebemos que o Programa associou uma concepção de educação à ideia de ampliação da jornada escolar, reconhecendo a importância da formação integral dos alunos. Mas à tal formação integral associou a proteção social, função que extrapola a natureza primeira da escola, emprestando-Ihe um caráter mais assistencial.

[...] nesse contexto [...] contemporâneo, a perspectiva de formação humana para a educação integral não está presente, necessariamente. Em outras palavras, ao propor, apoiar e reforçar a ampliação das funções da escola para além daquelas que historicamente a constituíram, a concepção contemporânea pode afastar-se de uma visão mais completa e multidimensional da formação do ser humano, no sentido pedagógico e crítico-emancipador do termo (COELHO, 2014, p. 188).

Isso porque, na perspectiva da autora:

[...] consideramos educação integral o trabalho educativo que entretece as várias possibilidades de conhecimento e saberes que consolidam, sóciohistoricamente falando, a formação humana. Essa formação se dá, não só, mas também na escola e, nesse espaço, ela é formal e intencional [...] (COELHO, 2014, p. 186).

A formação, no caso do PME, a fim de contemplar os já citados objetivos, ainda 
associava a educação integral a um currículo que partisse da realidade da comunidade na qual a escola estivesse inserida, do entrelaçamento entre diferentes culturas, saberes, identidades, valorizando a diversidade, relacionando os "saberes comunitários" e os "saberes escolares" (BRASIL, 2009a), o que revelava uma proposta de educação integral intercultural. A partir dessa ideia, o documento "Rede de Saberes Mais Educação" esclarece:

\begin{abstract}
A interculturalidade remete ao encontro e ao entrelaçamento, àquilo que acontece quando os grupos entram em relação de trocas. Os contextos interculturais permitem que os diferentes sejam o que realmente são nas relações de negociação, conflito e reciprocidade. Escola e comunidade são desafiadas a se expandirem uma em direção a outra e se completarem (BRASIL, 2009b, p. 21).
\end{abstract}

Tanto é que agentes educativos, como monitores, educadores populares, estudantes em processo de formação docente, estudantes de EJA e do Ensino Médio e agentes culturais que fossem referências em suas comunidades por suas práticas em diferentes campos, tiveram espaço de atuação no PME, na forma de um trabalho voluntário ${ }^{6}$ (BRASIL, 2009c). A coordenação ficava por conta do professor comunitário, que se tratava de um professor do quadro efetivo da rede de educação que aderisse ao Programa, com preferencialmente 40 horas semanais (BRASIL, 2009a).

Para a ampliação do cenário educativo e das oportunidades formativas oferecidas por essas escolas, as atividades socioeducativas propostas pelo PME se organizavam em "macrocampos" que, considerando as peculiaridades do território, possuíam orientações para as escolas do campo e urbanas no "Manual de educação integral 2014" (BRASIL, 2014b). Para as escolas urbanas, caso da escola pesquisada, as atividades a serem oferecidas deveriam ser inseridas no macrocampo Acompanhamento Pedagógico, de caráter obrigatório, e em outros três, a serem escolhidos dentre os seguintes: Comunicação, Uso de Mídias e Cultural Digital e Tecnológica; Cultura e Artes e Educação Patrimonial; Educação Ambiental, Desenvolvimento Sustentável, e Economia Solidária e Criativa/ Educação Econômica (Educação Financeira e Fiscal); Esporte e Lazer; Educação em Direitos Humanos; Promoção da Saúde (BRASIL, 2014). Para Silva e Silva (2014), essa forma de conceber política de educação integral, que

${ }^{6}$ Sob regência da lei n. 9.608, de 1998, que dispõe sobre voluntariado. Disponível em: http://www.planalto.gov.br/ccivil_03/leis/L9608.htm. Acesso em: 12 set. 2014. 
subordina a política à cultura, conferindo centralidade às diferenças culturais, tem forte influência do pensamento pós-moderno, sem que haja um questionamento das condições materiais que historicamente condicionaram as políticas de silenciamento e exclusão, as quais busca combater. Nesse sentido, os autores argumentam que:

Aceitar acriticamente a pluralidade de narrativas desqualifica a escola, 0 trabalho do professor, além de esfacelar o currículo, sobretudo da escola pública, através de esvaziamentos, reducionismos e/ou tentativas de transformar em consensos, conflitos subjacentes e que passam a fazer parte do currículo oculto da escola (SILVA; SILVA, 2014, p. 109).

Assim, no âmbito dessa configuração da escola, em que o ensino fica subsumido na aprendizagem e que a escola perde seu protagonismo, está a oposição recorrente, na concepção pragmática e em meios pós-modernos, entre instrução e educação, em que a instrução estaria restrita à dimensão cognitiva, enquanto que a educação se ateria à formação do caráter, da cidadania, para a vida social de modo a estender-se para a vida dos alunos, como afirma Libâneo, (2014).

É possível perceber, com Libâneo (2016), a proposta de educação integral em tempo integral do PME como estratégia do Estado para solução de problemas sociais e econômicos que venham afetar a ordem social e política; a menção de que o Estado divida, com a sociedade e com as comunidades, as responsabilidades pela escola pública; a associação do uso da escola para controle político e social, secundarizando o processo de ensino aprendizagem, as questões de conteúdo e método; promovendo, assim, o desfiguramento do espaço escolar. O autor assevera ainda que:

Considerar a escola apenas lugar de proteção social, de vivências socioculturais e de atendimento às diferenças e à diversidade social e cultural, a reduz meramente a uma referência física para colocar em prática projetos sociais do governo, ações socioeducativas e compensatórias voltadas para a população de baixa renda. Com isso, fica diluído seu papel de promover, por meio do ensino-aprendizagem, o domínio de conhecimentos, habilidades e atitudes e, com base nesse domínio, o desenvolvimento mental, afetivo e moral dos alunos. Fora de uma visão de escola voltada para o conhecimento, a aprendizagem e o desenvolvimento das capacidades intelectuais, é inútil falar em ampliação da jornada escolar ou em superação das desigualdades sociais e reconhecimento e respeito à diversidade (LIBÂNEO, 2016, p. 56). 
A partir dessa análise do $\mathrm{PME}$, o próximo tópico apresenta traços da materialização dessa proposta na escola pesquisada.

\section{Escola Municipal Flamingo7: palco do Programa Mais Educação}

A pesquisa em questão foi desenvolvida entre 2013 e 2014, na Rede Municipal de Educação de Ponte Nova, município brasileiro do estado de Minas Gerais que, à época, implementava o PME em três escolas para alguns alunos do Ensino Fundamental, reproduzindo seu caráter focal. Indo além da ação voluntária, algumas funções públicas para o desenvolvimento das atividades específicas do PME em Ponte Nova foram normatizadas pela lei municipal n. 3.739, de 2013 (PONTE NOVA, 2013) ${ }^{8}$, que instituiu a contratação, por tempo determinado, de professor comunitário, assistente de acompanhamento pedagógico para a atuação no macrocampo de Acompanhamento Pedagógico - e auxiliar de serviços gerais.

No que se refere à escola pesquisada, é localizada numa região periférica do município, onde há alto índice de vulnerabilidade social e de tráfico de drogas. O IDEB da instituição (5.0) foi o menor entre as demais instituições municipais da cidade disponíveis para consulta ${ }^{9}$, em 2013, e encontrava-se abaixo do IDEB municipal relativo aos anos iniciais do Ensino Fundamental (6.0), embora tenha superado as metas projetadas.

Em setembro de 2014, a escola possuía um total de 568 alunos, abrangendo a Educação Infantil e o Ensino Fundamental. A adesão ao PME se deu em 2012, sendo que, em 2013, esta oferta abarcava $27,6 \%$ dos alunos da escola, o que representava $60 \%$ dos alunos dos anos iniciais do Ensino Fundamental em jornada escolar diária de 8 horas e meia. Tivemos como foco da pesquisa as turmas compostas por alguns alunos do 4ㅇ ano e do 50 ano do turno

\footnotetext{
${ }^{7} \mathrm{~A}$ fim de preservar a identidade da escola, o nome exposto é fictício. Os dados que este tópico apresenta são fruto da observação realizada em relação às atividades do PME nessa escola e foram levantados e registrados em diário de campo no período entre 19 maio de 2014 a 22 agosto de 2014. O tópico também apresenta informações advindas da entrevista efetuada com a diretora e com a professora comunitária da escola, em setembro de 2014; de questionário aplicado à Secretária Municipal de Educação de Ponte Nova e à professora comunitária da escola, em setembro de 2014. ${ }^{8}$ Disponível em: http://www.pontenova.mg.gov.br/home/index/principal/noticia.asp?id_texto=637898. Acesso em: 27 maio 2018.

${ }^{9}$ Disponível em: http://ideb.inep.gov.br/resultado/home.seam?cid=6335829. Acesso em: 27 maio 2018.
} 
regular, que eram contempladas pelas atividades do projeto no período entre $11 \mathrm{~h} 30$ e $15 \mathrm{~h} 30$, após o horário regular.

No início da materialização do PME, segundo a diretora, a dimensão do improviso imperava, o que foi atenuado com a construção de duas salas de aula para os alunos do $1^{\circ}$ ao $5^{\circ}$ ano que permaneciam em tempo integral. Outros espaços da escola eram utilizados, como pátio, quadra, biblioteca e sala de informática, mas outros, como grama, corredores e áreas abertas foram identificados, pela assistente e voluntárias, como inapropriados diante da indisciplina dos alunos. Também observamos a ressignificação de espaços debaixo de mesas e cadeiras, comumente ditos "não lugares" para se brincar, o que demonstrava uma compreensão destoante da proposta do PME, que buscava superar a lógica marcada por espaços delimitados rigidamente (BRASIL, 2011).

Fora da escola também não era lugar de aprender, devido ao "alto nível de perigo" do bairro, conforme indicou a diretora. Advertem Gabriel e Cavaliere (2012) que a localização das escolas em regiões empobrecidas, o que era comum no PME, dificultava a busca por novos espaços e parceiros socioeducacionais, também inexistentes no âmbito da escola pesquisada.

As observações nos indicaram que eram obstáculos à ampliação dos espaços educativos, tanto a falta de estrutura da escola, como a falta de equipamentos educativos no bairro e de condições de segurança para o trânsito dos alunos. A concepção de espaço educativo de sujeitos envolvidos na materialização do Programa foi outro entrave observado; neste caso, restringindo os espaços educativos na própria escola.

No que tange aos macrocampos desenvolvidos no ano de 2014, para além do de Acompanhamento Pedagógico, a escola desenvolveu Esporte e Lazer e Cultura e Artes e Educação Patrimonial, cujas escolhas se basearam nos espaços e nos voluntários disponíveis e, num segundo plano, conforme a professora comunitária, no interesse dos alunos. Isso demonstrou que a formação ampliada, nos moldes do PME, no caso da escola pesquisada, tomou os contornos das possibilidades educativas daquela comunidade escolar. Perguntamonos como um Programa que fica à mercê das peculiaridades de cada comunidade, de cada escola, pode se afirmar como uma proposta de educação integral em tempo integral. Questionamos se qualquer condição, atividade - e forma de se trabalhar tais atividades-, 
espaço e voluntário são capazes de contemplar a integralidade formativa dos sujeitos, vale dizer, no âmbito da educação escolar. Ampliando nossas inquietações destacamos com os autores:

[...] é preciso considerar também o fato de o Governo Federal se colocar na posição de apenas "indutor" do Programa Mais Educação, responsabilizando os estados e municípios pelo provimento das condições, as quais julga cruciais ao sucesso da iniciativa, como a valorização docente, a regulamentação do piso salarial e o incremento do financiamento. Mesmo não ignorando que cada ente federativo tem atribuições e responsabilidades constitucionais específicas no que se refere ao financiamento das políticas educacionais, o fato de a valorização do trabalho docente não ser um critério para a implantação do Programa, juntamente com os precários dispositivos criados para garantir o funcionamento da jornada ampliada nas escolas, nos leva a considerar essa função indutora como uma faceta do processo de desobrigação da União no que se refere às políticas sociais [...]. Um exemplo disso é a utilização do artifício do voluntariado pelo Programa, como uma "indução" à precarização e à desprofissionalização do trabalho docente (SILVA; SILVA, 2014, p. 104).

Observamos, no caso da escola pesquisada, várias situações que demonstravam a fragilidade que acarretava, na materialização do PME, a falta de profissionais preparados e de espaços adequados. Na oficina de Acompanhamento Pedagógico, prevaleciam o dever de casa e a cópia de exercícios do quadro, com grande predominância das áreas de português e matemática, não contemplando todas as atividades/áreas do conhecimento previstas ${ }^{10}$ para o macrocampo. Foi possível observar a procura, pelas crianças, por brincadeiras com diversos jogos, que não eram incentivadas. Uma ação realizada com frequência por algumas crianças do sexo feminino, nessa oficina, era a limpeza da sala com vassouras, algumas vezes a pedido da assistente, outras, de forma espontânea. Também não constatamos a articulação do currículo com as atividades do PME. Podemos dizer, assim, que a oficina não buscava ampliar o arcabouço formativo das crianças para além do já trabalhado no regular e incentivar seus interesses. Delegava-se às meninas, inclusive, tarefa incondizente com o papel da escola, a exemplo da limpeza da sala.

A oficina de Percussão, do macrocampo de Cultura e Artes e Educação Patrimonial, era

${ }^{10}$ O “Manual operacional de educação integral 2014” (BRASIL 2014b) previa, para esse macrocampo, as atividades: Orientação de Estudos e Leituras, a contemplar as diferentes áreas do conhecimento (Alfabetização, Matemática, Histórias, Ciências, Geografia, Línguas Estrangeiras e outras).

Argumentos Pró-Educação, Pouso Alegre, v. 4, n. 12, p. 1097 - 1117, set. - dez., 2019

ISSN: 2448-2803 http://dx.doi.org/10.24280/ape.v4i12.408 
ministrada, ora por um voluntário de uma ONG, envolvendo a prática com instrumentos e orientações sobre seu uso e sobre a postura para tocá-los, ora pela monitora de Esporte e Lazer, envolvendo, por um lado, atividades esportivas, por outro, a nomeação oral e escrita de instrumentos e demonstração de seu uso. Nessa oficina, foi possível perceber o interesse de algumas crianças e de outras não, o que revelou a necessidade do trabalho com outros instrumentos, além de métodos educativos que envolvessem os alunos, contribuindo para seu desenvolvimento enquanto sujeitos ativos. O trabalho com atividades esportivas no horário de Percussão era outra constante que limitava a ampliação do conhecimento relacionado a essa oficina.

A oficina de Desenho, do macrocampo de Culturas e Artes e Educação Patrimonial, ocorria fora e dentro da sala de aula. Observamos atividades como cópia de desenho, pintura orientada, técnicas de colorido e pintura na parede. Foram expostas, via meio digital, obras de artistas plásticos brasileiros e internacionais. A expressão livre dos alunos no desenho e na pintura era muitas vezes tolhida por meio das atividades de cópia, indicando a necessidade de formação pedagógica por parte da voluntária que, mesmo sem ela, procurava envolver os alunos e promover uma continuidade e uma constante contextualização das atividades que eram desenvolvidas, bem como diálogos sobre a vida extraescolar e a organização da sala.

$\mathrm{Na}$ oficina de Esporte e Lazer, observamos atividades como futebol, basquete, peteca, totó, circuito de jogos, queimada e pula-corda, ocorrendo em espaços como o gramado da escola, pátio e quadra, nesse caso quando não ocupados pelos alunos do ensino regular. Era comum, durante as atividades desse macrocampo, as meninas jogarem peteca e os meninos futebol, enquanto a voluntária jogava algum dos jogos com um dos grupos ou ficava observando, exceto no circuito de jogos, quando havia, em geral, envolvimento coletivo. Percebemos que, nessa oficina, aqueles alunos que não apreciavam nenhuma das atividades ficavam observando, o que revelava a necessidade de um planejamento inclusivo em relação a eles.

Atividades como leitura, ensaio de teatro, encenação de histórias com fantoches e decoração de caixa de contação de histórias eram recorrentes na oficina de Teatro, no período de nossa pesquisa de campo. Era regular a avaliação oral acerca da habilidade de leitura dos 
alunos, levando, muitas vezes, a sua exclusão em atividades que a exigiam. Se, para a voluntária, as crianças cotidianamente gritavam durante as atividades e possuíam diferentes níveis na habilidade de leitura, a oficina de Teatro seria um oportuno momento para se trabalhar a linguagem, as múltiplas formas que as crianças usam para se expressar, demonstrar o que sentem e pensam sobre o mundo que as cerca, reconhecendo a peculiaridade do desenvolvimento dos alunos, elementos circunscritos aos objetivos do próprio Programa (BRASIL, 2009a, 2011). A conversa e a utilização de materiais da sala eram eventos comuns, mas ditos incongruentes à oficina, avaliados como expressão de "brincadeira", às quais, conforme a voluntária, era atividade relativa ao esporte e à percussão, o que além de reduzir a oficina de Esporte e Lazer e de Percussão à brincadeira, "retirava" da oficina de Teatro a dimensão da ludicidade, como se ela não fosse algo sério e importante na formação integral das crianças.

Momentos enfatizando brincadeiras entre as turmas, com envolvimento coletivo da professora comunitária e dos voluntários, era alvo de acentuada interação dos alunos, o que era coibido no momento do intervalo entre turno e contraturno, quando foi possível observar a orientação para a realização do dever de casa para os que o possuíam e de "silêncio" para o demais. Brincadeiras com figurinhas ou no quadro, uso de esmalte, produção de dobraduras, desenho, leitura de livros de história, entre outras, eram atividades comuns nesse momento, não sendo incentivadas nem contextualizadas aos conhecimentos trabalhados naquele momento, ou posteriormente. Ainda no que tange a brincadeiras e brinquedos, também foi possível observar a coibição do uso de brinquedos trazidos de casa, mesmo que a proposta do PME pretendesse conferir legitimidade às condições culturais dos alunos, valorizando suas experiências, seus saberes, seus costumes e suas práticas (BRASIL, 2009a). Pudemos perceber em algumas circunstânciasum programa de educação integral em tempo integral sendo palco de repressão das vontades e necessidades dos alunos, além de tempo, vale dizer, mais tempo de ficar sentado, ficar calado, copiar, escrever.

Conforme Borba (2007), se vinculamos a brincadeira a um tempo perdido, enxergandoa como improdutiva e em oposição ao trabalho por sua falta de resultados, podemos afirmar que seu não incentivo, no contexto da pesquisa, atribui um caráter eficientista à proposta 
pedagógica do PME, quando materializada em determinadas circunstâncias e condições escolares específicas ${ }^{11}$. Mas, se consideramos o brincar como tempo/espaço de apropriação e constituição de conhecimentos e habilidades no âmbito da linguagem, da cognição dos valores e da sociabilidade, e, ainda, ligado à formação das crianças como sujeitos culturais e à constituição de culturas em espaços e tempos em que convivem no cotidiano, conforme considera Borba (2007), sua falta vai de encontro à possibilidade de sua constituição na "inteireza" das crianças.e

\begin{abstract}
Também essa possibilidade vai de encontro à falta de articulação entre turno e contraturno, prevista pelo parágrafo único do artigo 166 do Regimento Escolar (2014) da escola pesquisada: “Os campos de conhecimento da Educação em Tempo Integral devem estar integrados aos Componentes Curriculares das áreas de conhecimento do Ensino Fundamental". Conforme a professora comunitária, isso se dava pela possibilidade de os alunos fazerem as atividades que encontravam dificuldades no período regular e aquelas que foram direcionadas para a casa, mas que não possuíam quem os auxiliasse, "é a extensão da casa", disse ela.
\end{abstract}

Observamos, assim, que tal integração se dava em nível de reforço escolar e de apoio nos deveres de casa, não se configurando um planejamento conjunto, de forma que turno e contra turno se complementassem, e que as múltiplas dimensões formativas fossem pensadas e planejadas na integração dos conhecimentos, como eixo estruturador de uma educação integral em tempo integral. Nesse sentido:

\begin{abstract}
Em relação às atividades, acreditamos que somente oferecê-las aos alunossujeitos, de forma indiscriminada e, por vezes, fragmentada, sem que um envolvimento maior as exija, é uma atitude que não favorece a qualidade a que nos referimos. Em outras palavras, acreditamos que atividades que sejam demandadas pelos alunos serão sempre mais significativas do que aquelas que a escola considera, por diversos motivos, como as possíveis de serem oferecidas e, nesse sentido, o esforço da gestão escolar para organizá-las e levá-las até esses alunos se faz necessário e imprescindível (COELHO; FERNANDES, 2013, p. 166)
\end{abstract}

Tais alunos, nos parece, não eram ouvidos em suas demandas, o que no remete a uma prática recorrente durante as atividades: a suspensão de alunos das atividades do projeto.

\footnotetext{
${ }^{11}$ Uma vez que não é possível generalizar os resultados desta pesquisa para as demais escolas do município e para outras redes e sistema de ensino.
} 
Durante a observação, verificamos motivos de suspensão como briga entre crianças, agressão verbal, realização de atividades de forma "errada", além do trânsito em espaços da escola.

Nos parece, ainda, ter sido a razão maior para a contradição entre a prática da suspensão e a proposta do PME seu objetivo de promover a inclusão social e educacional de crianças e tal prática, nesses momentos observados, ter contribuído para com a exclusão dessas crianças no interior do PME. Assim,

\begin{abstract}
Ao retirar da escola pública o seu papel produtor de desigualdades sociais e depositar nela um papel de inclusão (apenas), a resposta sobre os motivos da educação integral no contexto atual deixam de, também, -levar em consideração que isso que está sendo chamada de educação integral não está livre das contradições dos dias atuais sendo, inclusive, incorporado ao cotidiano de produção da desigualdade hoje existente na escola pública (SILVA, 2013, p. 163).
\end{abstract}

Nesse sentido, outra prática, também verificada no contexto da consecução do projeto, era intitulada "castigo", que gerava punições como, por exemplo, as que observamos: proibição de frequência na oficina de Esporte e Lazer, Teatro, Percussão e Desenho; "mais" cópia de textos; "mais" leitura; "mais" atividades de Matemática ou dever de casa; realização da alimentação fora do grupo; extinção do lanche ou almoço, por motivos como alguns que observamos: não realização de atividade de Acompanhamento Pedagógico; manuseio de material do projeto sem permissão; saída da sala sem solicitação; desaparecimento de objeto na sala; não contribuição para recolhimento de objetos da sala. Tais medidas foram observadas sendo empreendidas por voluntários, professora comunitária e assistente de Acompanhamento Pedagógico.

Os tipos de castigo empregados, além de passearem por ações que solapam direitos das crianças na escola, em sua maioria se circunscreviam a atividades oferecidas no macrocampo de Acompanhamento Pedagógico, revelando, mais uma vez, a ênfase nesta área. À medida que as atividades desse macrocampo se configuravam, ao mesmo tempo, como razão e consequência de castigo, verificamos uma contradição com a proposta do PME, de uma educação integral em tempo integral.

Tal ênfase nas áreas de Português e Matemática era acompanhada da falta de elementos pedagógico-didáticos, inclusive, para se trabalhar este enfoque. Para Libâneo 
(2014), esta falta caracteriza uma grande debilidade das propostas de escola de tempo integral brasileiras. $\mathrm{O}$ autor defende uma escola em que os alunos realizem atividades de estudo, que aprendam a ter uma relação com o conhecimento, vale dizer, aquele conhecimento voltado para o processo mental, como meio de desenvolvimento de capacidades intelectuais.

Entendemos, assim, que no período observado, a escola pesquisada implementou o PME com enfoque em áreas como Português e Matemática, demandando a "disciplina" dos alunos em relação àquilo se colocava como dever deles na escola, reproduzindo as práticas do castigo e da suspensão no caso de sua "indisciplina", parecendo, deste modo, tendenciosa à prática da exclusão social dentro da escola, privando as crianças do acesso ao conhecimento organizado em áreas necessárias para uma educação integral. A partir desta narrativa, sobre o cotidiano de uma escola que recebe o PME em Ponte Nova/MG, apresentamos, no tópico seguinte, algumas reflexões mais gerais acerca dessa experiência, relacionando-as ao arcabouço teórico com que trabalhamos.

\section{Considerações finais}

Concluímos duvidando da educação em tempo integral como fator propiciador de uma educação integral, pelo menos no que se relaciona à experiência vivenciada na escola pesquisada. Percebemos que a justificativa para a escola de tempo e horizonte formativo ampliado, na perspectiva de Leclerc e Moll (2013), não se mantém nessa escola; pois, como argumentam:

[...] o tempo compõe o cenário para a restituição de humanidade ao ato de educar, na medida em que mais tempo, e mais tempo ressignificado, pode ensejar diálogos em que cada um diga de si, de sua vida e história, compondo os mosaicos próprios da diversidade, historicamente silenciados na vida escolar. E, nesse sentido, a educação referenciada nos seus sujeitos poderá recuperar o ser humano como referência, apontando para transformações societárias que passam inevitavelmente para a escola (LECLERC; MOLL, 2013, p. 293).

Concordamos com Libâneo (2014), quando ele afirma que a escola de tempo integral, para propiciar educação integral, precisa assumir seu papel de promoção da educação e do 
ensino com vistas ao desenvolvimento mental e à formação da personalidade dos alunos. $E$, para isso, demarcamos com o autor, uma série de investimentos necessários "às escolas comuns" - anteriormente das escolas de tempo integral - subjacentes à estrutura física, aos equipamentos, à parte administrativa, à parte pedagógica, à remuneração dos professores, à formação de professores em serviço, à gestão pedagógico curricular, às condições de ensinoaprendizagem, à assistência pedagógica ao professor em sala de aula, à infraestrutura e material.

Parece-nos, nesse sentido, inviável uma proposta que abdica desses investimentos em sua implementação. Se a "escola comum" vem sinalizando sua dificuldade na oferta de uma "educação comum" de qualidade, perguntamo-nos como um programa pretende oferecer mais do que o comum com menos recursos. Outro ponto nos chama a atenção e ele passa pelo fato de a concepção de educação integral em tempo integral do PME carregar a pretensão de ampliar o horizonte formativo dos alunos secundarizando a natureza própria da escola: trabalhar com a educação de forma intencional, pedagógica e sistemática, haja visto o incentivo às parcerias com instituições não necessariamente de teor educativo e à atuação de sujeitos que não docentes.

Observamos que as condições para implementação do PME não colaboram com a não hierarquia dos saberes e conhecimentos, de forma a se considerar todas as dimensões de formação num mesmo patamar. No contexto da escola pesquisada, essa inferência se fez visível, se consideramos que as oficinas, exceto aquela de Acompanhamento Pedagógico, se circunscreviam a macrocampos e atividades escolhidas em primeiro plano, conforme o espaço e as habilidades dos agentes educativos. Não sendo critério para sua implementação a estruturação das escolas e a atuação de profissionais preparados para sua consecução, as áreas curriculares a ampliarem o horizonte formativo dos alunos não eram escolhidas a partir do interesse dos discentes, nem do que se presumia contemplar suas múltiplas dimensões de formação.

Nessa perspectiva, cabe observar que as tensões vividas na escola não são exclusivas do PME; ao contrário, muitas vezes, o que ocorre é uma repetição do turno regular de forma piorada, uma vez que este programa não contava com profissionais preparados para lidar com 
as questões didático-pedagógicas que interpelavam o cotidiano escolar, nem com espaços condizentes com a educação que se pretendia oferecer. Se consideramos que nem os professores são preparados para tanto, nos perguntamos como poderia o PME presumir que voluntários o seriam?

Contudo, mesmo frente ao exposto, consideramos que a educação "a mais" que o PME propunha, apesar de todas as limitações, representou um importante marco no sentido de suscitar reflexões sobre a importância de a escola abarcar outras áreas da formação, além das que integram o ensino regular, áreas estas que, na perspectiva de muitos alunos, são muito interessantes. Mas, ao mesmo tempo em que vislumbramos o início da valorização dessas áreas, percebemos também que seu oferecimento se limita a alguns alunos, a algumas escolas, em condições mais precárias que o ensino regular.

Finalizamos com Silva (2013), pontuando que não se trata de negar a possibilidade de que o programa tenha propiciado melhorias localizadas e feito a diferença na vida dos alunos, dada a possibilidade de melhorias com a chegada de recursos, mas é necessário sinalizar que junto a esses recursos chegaram também situações deletérias ao curso da democratização da educação pública, que são difíceis de ser consideradas avanços. Nesse sentido, o autor chama a atenção para a dependência a que foram submetidas as condições gerais de implementação do Programa, da "boa vontade" dos sujeitos envolvidos e das circunstâncias locais das escolas, em detrimento da ação do poder público nas esferas federal, estadual ou municipal. Escolhendo a segunda opção da questão: “Ora, pensemos: educação integral é uma estratégia, ou ao contrário, é raiz da formação do ser humano?” (COELHO, 2012, p. 86), no contexto do PME salientamos que a educação a mais proposta pareceu se configurar mais como uma justificativa ideológica para outros fins, tal como o acolhimento social, do que para fundamentar filosoficamente a educação integral vista como raiz da formação humana. 


\section{Referências}

BOGDAN, R. C.; BIKLEN, S. Investigação qualitativa em educação. 4. ed. Tradução Maria J. Alvez, Sara B. dos Santos e Telmo M. Baptista. Porto: Porto Editora, 1994.

BORBA, A. M. O brincar como um modo de ser e estar no mundo. 2. ed. Brasília: MEC, 2007. Disponível em:

http://portal.mec.gov.br/seb/arquivos/pdf/Ensfund/ensifund9anobasefinal.pdf. Acesso em: 30 abr. 2018.

BRASIL. Portaria Normativa Interministerial n. 17, de 24 de abril de 2007. Institui o Programa Mais Educação que visa fomentar a educação integral de crianças, adolescentes e jovens, por meio do apoio a atividades socioeducativas no contraturno escolar. Diário Oficial da União, Brasília, DF, 26 de abril de 2007. Disponível em:

http://portal.mec.gov.br/arquivos/pdf/mais_educacao.pdf. Acesso em: 27 maio 2018.

BRASIL. Ministério da Educação. Programa Mais Educação: Manual passo a passo. Brasília, D.F: MEC, 2009a. Disponível em:

http://portal.mec.gov.br/dmdocuments/passoapasso_maiseducacao.pdf. Acesso em: 27 maio 2018

BRASIL. Ministério da Educação. Série Mais Educação: Rede de Saberes Mais Educação Pressupostos para Projetos Pedagógicos de Educação Integral. Brasília: MEC, 2009b. Disponível em: http://portal.mec.gov.br/dmdocuments/cad_mais_educacao_2.pdf>. Acesso em: 27 maio 2018.

BRASIL. Ministério da Educação. Série Mais Educação: gestão intersetorial no território. Brasília: MEC/Secretaria de Educação Continuada, Alfabetização e Diversidade, 2009c. Disponível em: http://portal.mec.gov.br/dmdocuments/cader_maiseducacao.pdf. Acesso em: 27 maio 2018.

BRASIL. Decreto n. 7.083 de 27 de janeiro de 2010. Dispõe sobre o Programa Mais Educação. Diário Oficial da União, Brasília, DF, 27 de janeiro de 2010. Disponível em: http://www.planalto.gov.br/ccivil_03/_ato2007-2010/2010/decreto/d7083.htm. Acesso em: 27 maio 2018.

BRASIL. Ministério da Educação. Mais Educação: Cartilha caminhos para elaborar uma proposta de educação integral em jornada ampliada. Brasília: SEB/MEC, 2011. Disponível em:

http://portal.mec.gov.br/index.php?option=com_docman\&view=download\&alias=8194-4caminhos-elaborar-educacao-integral-cecipe-seb-pdf\&category_slug=junho-2011pdf\&Itemid=30192. Acesso em: 27 maio 2018.

BRASIL. Resolução n. 2, de 14 de abril de 2016. Destina recursos financeiros, nos moldes 
operacionais e regulamentares do Programa Dinheiro Direto na Escola (PDDE). Diário Oficial da União, Brasília, DF, 14 de abril de 2016. Disponível em: https://www.fnde.gov.br/fndelegis/action/UrlPublicasAction.php?acao=abrirAtoPublico\&sgl _tipo=RES\&num_ato=00000002\&seq_ato $=000 \& v 1 r \_a n o=2016 \& s g \mid$ orgao=CD/FNDE/MEC. Acesso em: 27 maio 2018.

BRASIL, Ministério da Educação: Manual operacional de educação integral 2014. Diário Oficial da União. Brasília, DF, 2014. Disponível em: http://portal.mec.gov.br/index.php?option=com_content\&view=article\&id=16690\&/temid= 1113. Acesso em: 27 maio 2018.

BRASIL. Ministério da Educação. Programa Mais Educação: Impactos na Educação Integral e Integrada. 2013. Relatório de Pesquisa interinstitucional com UFG, UFMG, UFPA, UFPE, UFPR, UNIRIO. 135 p. Disponível em:

http://educacaointegral.mec.gov.br/images/pdf/pesquisa_ufmg_relatorio_final.pdf. Acesso em: 27 maio 2018.

CAVALIERE, A. M. V. Educação integral como "política especial" na educação brasileira. In: COELHO, L. M. C. C. (org.). Educação integral: história, políticas, práticas. Rio de Janeiro: Rovelle, 2013. p. 225-242.

CAVALIERE, A. M. V. Tempo de escola e qualidade na educação pública. Educ. Soc., Campinas, v. 28, n. 100 Especial, p. 1015-1035, out. 2007. Disponível em www.scielo.br/pdf/es/v28n100/a1828100.pdf. Acesso em: 27 maio 2018.

COELHO, L. M. C. C. Alunos no ensino fundamental, ampliação da jornada escolar e educação integral. Educar em Revista, Curitiba, v. 45, p. 73-89, 2012. Disponível em:

http://www.scielo.br/scielo.php?pid=S0104-40602012000300006\&script=sci_arttext. Acesso em: 27 maio 2018.

COELHO, L. M. C. C. Integração escola-território: "saúde" ou "doença" das instituições escolares? In: MAURíCIO, L. V. M. (org.). Tempos e espaços escolares. Experiências, políticas e debates no Brasil e no mundo. Rio de Janeiro: Ponteio; FAPERJ, 2014.v. 1, p. 181-198.

COELHO, L. M. C. C.; FERNANDES, C. F. Mais anos na escola, mais tempo diário na escola: qualidade no ensino fundamental? Cadernos de Educação, Pelotas, v. 44, p. 150-171, 2013. Disponível em: http://periodicos.ufpel.edu.br/ojs2/index.php/caduc/article/view/2743. Acesso em: 27 maio 2018.

GABRIEL, C. T; Cavaliere, A. M. V. Educação integral e currículo integrado: quando dois conceitos se articulam a um programa. In: MOLL, J. (org.). Caminhos da educação integral no Brasil: direito a outros tempos e espaços educativos. Porto Alegre: Penso, 2012. p. 277294. 
LECLERC, G. F. E.; MOLL, J. Diversidade e tempo integral: a garantia dos direitos sociais.

Retratos da Escola, v. 7, p. 291-304, 2013. Disponível em:

http://retratosdaescola.emnuvens.com.br/rde/article/view/306/476. Acesso em: 27 maio 2018.

LIBÂNEO, J. C. Escola de tempo integral em questão: lugar de acolhimento social ou ensinoaprendizagem? In: VALDENIZA, M. L. B. (org.). Educação: ensino, espaço e tempo na escola de tempo integral. Goiânia: Gráfica UFG, 2014. p. 257-308.

LIBÂNEO, J. C. Políticas educacionais no Brasil: desfiguramento da escola e do conhecimento escolar. Cadernos de Pesquisa (Fundação Carlos Chagas), v. 46, p. 38-62, 2016. Disponível em: http://www.scielo.br/pdf/cp/v46n159/1980-5314-cp-46-159-00038.pdf. Acesso em: 27 maio. 2018.

MOLL, J. A agenda da educação integral: compromissos para sua consolidação como política pública. In: MOLL, J. (org.). Caminhos da educação integral no Brasil: direito a outros tempos e espaços educativos. Porto Alegre: Penso, 2012. p. 129-143.

PONTE NOVA. Lei n 3.739 de 25 de março de 2013. Dispõe sobre a criação de funções públicas para o desenvolvimento das atividades específicas do Programa Federal Mais Educação e dá outras providências. Diário Oficial do Município, Ponte Nova, MG, 25 de março de 2013. Disponível em:

http://www.camarapontenova.mg.gov.br/ler_legislacao.asp?id=3331. Acesso em: 29 mar. 2015.

SILVA, B. A. R. Interesses, dilemas e a implementação do Programa Mais Educação no município de Maricá (RJ). 275 fls. 2013. Tese (Doutorado em Educação) - Programa de PósGraduação em Educação da Universidade Federal do Rio de Janeiro, Rio de Janeiro, 2013. Disponível em: http://www.educacao.ufrj.br/dissersandraramaldo.pdf. Acesso em: 27 maio 2018.

SILVA, J. A. A.; SILVA, K. N. P. Analisando a concepção de Educação Integral do governo Lula/Dilma através do Programa Mais Educação. Educação em Revista, Belo Horizonte, v. 30, p. 95-126, 2014. Disponível em: http://www.scielo.br/scielo.php?pid=S010246982014000100005\&script=sci_arttext. Acesso em: 27 maio 2018.

Recebido em: 06/07/2018

Aprovado em: 20/03/2019 